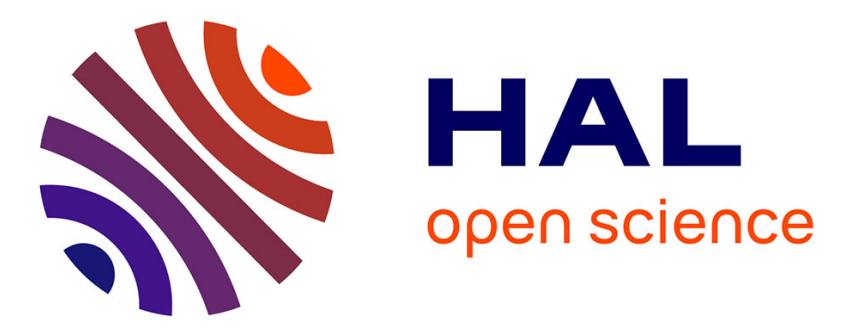

\title{
Quasi-continuous waveform design for dynamic range reduction
}

\author{
Rami Kassab, Marc Lesturgie, Jocelyn Fiorina
}

\section{To cite this version:}

Rami Kassab, Marc Lesturgie, Jocelyn Fiorina. Quasi-continuous waveform design for dynamic range reduction. Electronics Letters, 2008, 44 (10), pp. 646-648. 10.1049/el:20083476 . hal-00355231

\section{HAL Id: hal-00355231 \\ https://hal-centralesupelec.archives-ouvertes.fr/hal-00355231}

Submitted on 22 Jan 2009

HAL is a multi-disciplinary open access archive for the deposit and dissemination of scientific research documents, whether they are published or not. The documents may come from teaching and research institutions in France or abroad, or from public or private research centers.
L'archive ouverte pluridisciplinaire HAL, est destinée au dépôt et à la diffusion de documents scientifiques de niveau recherche, publiés ou non, émanant des établissements d'enseignement et de recherche français ou étrangers, des laboratoires publics ou privés. 


\section{Quasi-continuous waveform design for dynamic range reduction}

Rami Kassab, M. Lesturgie and Jocelyn Fiorina

A study of quasi-continuous waveform (QCW) and its performance in detection is presented taking into consideration eclipsing loss and free space decay. Genetic algorithm is then used to optimise the waveform and lower the dynamic range of the matched filtering output. The resulting waveform with high duty cycle and minimal loss at maximal range maintains good detection performance along the whole operating range of the radar.

Introduction: In order to reduce the probability of intercept of radar transmissions, the strategy [1] consists in spreading the energy of emission in all possible dimensions. This explains why low probability of intercept (LPI) radars use continuous or even QCWs spreading the energy in time and lowering the peak power. QCWs have also the ability of overcoming the leakage problem by time-isolating the transmission and reception. This also means that the echoes are susceptible of being sheltered (eclipsed) during the emission, so QCWs are chosen to reduce this shelter loss as much as possible while maintaining high duty cycle [2]. However, two important issues have to be taken into consideration [3]. First, the shelter effect alters the ambiguity function (AF) which becomes range dependent. Second, the free space loss [4] which affects the echoes is not only responsible for their high dynamics but also makes it more difficult to tolerate the shelter loss for the far targets as much as for the closer ones. In the following we will investigate the design and properties of QCWs with range dependant AF considering the 
shelter loss and reducing the dynamic range requirements due to the free space decay.

Problem formulation: Let $a(t)$ be the complex envelope of the waveform whose magnitude takes the values 0 and $K$ for the blocked and saturated states of the transmitter respectively. This signal is shifted in time and frequency and attenuated by a complex factor $\alpha_{0}$ before reaching back the radar. Therefore, the envelope of the received signal is:

$$
s\left(t, \theta_{0}\right)=\alpha_{0} a\left(t, \theta_{0}\right)[1-|a(t)| / K]
$$

where $\theta_{0}=\left(d_{0}, v_{0}\right)$ is the shift in time and frequency due to the distance $d_{0}$ and the velocity $v_{0}$ of the target, $a\left(t, \theta_{0}\right)$ is the corresponding shifted envelope. Without loss of generality, in the following we will consider $K=1$.

The optimal receptor, in the presence of an additive white Gaussian noise (AWGN) $b(t)$ of power spectral density $N_{0}$, is based on a matched filtering therefore a normalised correlation with the model of the echoes whose output is:

$$
Q\left(\theta, \theta_{0}\right)=(1 / \operatorname{Pr}(\theta))\left|\int\left[\alpha_{0} a\left(t, \theta_{0}\right)+b(t)\right][1-|a(t)|] a^{*}(t, \theta) d t\right|^{2}
$$

where the energy profile $\operatorname{Pr}(\theta)$ is:

$$
\operatorname{Pr}(\theta)=\int|a(t, \theta)|^{2}[1-|a(t)|] d t
$$

As the samples of the received signal are forced to zero during transmission, noise is also cancelled over this period.

Let 


$$
\chi\left(\theta, \theta_{0}\right)=\int a\left(t, \theta_{0}\right) a^{*}(t, \theta)[1-|a(t)|] d t
$$

and

$$
X(\theta)=\left(1 /\left|\alpha_{0}\right|\right) \int b(t) a^{*}(t, \theta)[1-|a(t)|] d t
$$

then

$$
Q\left(\theta, \theta_{0}\right)=\left(\left|\alpha_{0}\right|^{2} / \operatorname{Pr}(\theta)\right)\left|\chi\left(\theta, \theta_{0}\right)+X(\theta)\right|^{2}
$$

$\chi\left(\theta, \theta_{0}\right)$, known as the AF, reaches its maximum for $\theta=\theta_{0}$ :

$$
\begin{gathered}
\chi\left(\theta_{0}, \theta_{0}\right)=\int\left|a\left(t, \theta_{0}\right)\right|^{2}[1-|a(t)|] d t=A-\int\left|a\left(t, \theta_{0}\right)\right|^{2}|a(t)| d t \\
=A\left[1-l\left(\theta_{0}\right)\right]=\operatorname{Pr}\left(\theta_{0}\right)
\end{gathered}
$$

with $A$ the energy of the transmitted signal over the integration interval and $l\left(\theta_{0}\right)$ the shelter loss function [2]. Hence, if we denote by $E$ the expected value operator then:

$$
\begin{aligned}
E\left[Q\left(\theta, \theta_{0}\right)\right]= & \left(\left|\alpha_{0}\right|^{2} / \operatorname{Pr}(\theta)\right)\left(\left|\chi\left(\theta, \theta_{0}\right)\right|^{2}+E\left[X(\theta) X^{*}(\theta)\right]\right) \\
& =\left(\left|\alpha_{0}\right|^{2} / \operatorname{Pr}(\theta)\right)\left|\chi\left(\theta, \theta_{0}\right)\right|^{2}+N_{0}
\end{aligned}
$$

Performance of detection: The detection decision is made by comparing $Q$ to a threshold $T$ [5]. The probability of detection $P_{d}$ is affected by the energy profile, while the probability of false alarm $P_{f a}$ remains unchanged. Their expressions, for a non fluctuating target, are given by:

$$
\begin{gathered}
P_{d}=\left[\int_{T}^{+\infty} \exp \left(-\left(x+\left|\alpha_{0}\right|^{2} \operatorname{Pr}(\theta)\right) / N_{0}\right) I_{0}\left(2 \sqrt{\left(x\left|\alpha_{0}\right|^{2} \operatorname{Pr}(\theta)\right)} / N_{0}\right) d x\right] / N_{0} \\
P_{f a}=\left[\int_{T}^{+\infty} \exp \left(-x / N_{0}\right) d x\right] / N_{0}=\exp \left(-T / N_{0}\right)
\end{gathered}
$$

where $I_{0}$ is the zero order modified Bessel function of the first kind. 
Waveform optimisation: The dynamic range of the output $Q$ and for a good signal to noise ratio $(>10 \mathrm{~dB})$ could be evaluated in the operating range of the radar by the ratio:

$$
R=\left[\max _{\theta} Q(\theta, \theta)\right] /\left[\min _{\theta} Q(\theta, \theta)\right]=\left[\max _{\theta}\left(|\alpha|^{2} \operatorname{Pr}(\theta)\right)\right] /\left[\min _{\theta}\left(|\alpha|^{2} \operatorname{Pr}(\theta)\right)\right]
$$

Since $|\alpha|^{2}$ is generally proportional to $d^{-4}$ the ratio will be minimal when the product of $|\alpha|^{2} \operatorname{Pr}(\theta)$ becomes constant and $\operatorname{Pr}(\theta)$ is proportional to $d^{4}$. Eventually, $\operatorname{Pr}(\theta)$ should be maximal in the operating range of the radar, and in some cases places a null at the range position of a strong scatterer as for the nadir echo in the case of the synthetic aperture radars. Given these different criteria of optimisation of the waveform in addition to the duty cycle and given the binary nature of $|a(t)|$ which defines $\operatorname{Pr}(\theta)$, the genetic algorithm seems to be a suitable optimisation technique.

Numerical simulation and analysis: Given a periodic codeword $a_{p}$ of length $N$, we consider a maximal range corresponding to a spatial shift of half the codeword, where $\operatorname{Pr}(i)$ would be maximal in its optimal case, with $i=1 . . N / 2$ the index of the distance bin. We therefore propose a penalty function (to be minimised) based on an aggregation [6] method which combines several performance criteria into a single one by means of a weighted sum parametered by $\rho, \alpha, \beta$ and $\gamma$ and given by:

$$
\begin{aligned}
& F\left(a_{p}\right)=|10 \log (R)-\rho|+\alpha|N / 2-\operatorname{Pr}(N / 2)|+\beta \max _{i=1 . . N}(C S(i)) \\
& \quad+\gamma\left|10 \log \left(\min _{i=1 . . N / 2}(Q(i) / Q(N / 2))\right)\right|
\end{aligned}
$$

where $\rho$ is the intended dynamic range, $\alpha, \beta$ and $\gamma$ are the weighting parameters. CS (Cumulative Sum) and $Q$ are as follow: 


$$
\begin{gathered}
C S(i)=\left|\sum_{k=1}^{k=i}\left(2 a_{p}(k)-1\right)\right| \\
Q(i)=i^{-4} \operatorname{Pr}(i)
\end{gathered}
$$

The second term in the penalty function pushes towards the optimal $50 \%$ duty cycle (best compromise between transmit and receive energy) and a zero shelter loss at maximal range. The third term spreads the energy in the codeword and thus prevents the trivial monopulse case. Finally, the fourth term when nullified places the minimal SNR which defines the maximal range where it is wished to be i.e. for $i=N / 2$.

Figure 1 shows the codeword resulting from the optimisation with $N=100$, $\rho=58, \alpha=\beta=0.2$ and $\gamma=2$. The codeword reached a duty cycle of $47 \%$, a zero loss at maximal range and a blind-range free energy profile which is shown in Figure 2. The output $Q$ has a dynamic of $58 \mathrm{~dB}$, so $10 \mathrm{~dB}$ less than the dynamic imposed by the free space loss between the first and the $50^{\text {th }}$ distance bin. Figure 3 shows the corresponding probability of detection in the presence of the free space loss for two cases of $P_{f a}$ corresponding to $10^{-2}$ and $10^{-5}$. As we tolerated a minimal probability of detection of 0.98 we notice that this probability is not reached before the maximal range, the range which is not affected by the shelter loss. Therefore, the shelter loss is having no effect on the radar power budget for this waveform.

Conclusion: A new penalty function has been proposed to establish a trade-off between the duty cycle and the shelter loss, the dynamic reduction and the 
energy spread in the codeword. We have shown that shelter loss could be managed in a QCW with a duty cycle up to $47 \%$ in order to reduce the dynamic range requirements, while maintaining good detection performance along the whole operating range of the radar. The resulting waveform has therefore enhanced LPI properties and is suitable for monostatic radars with wide operating range.

\section{References}

1 STOVE, A.G., HUME, A.L., and BAKER, C.J.: 'Low probability of intercept radar strategies', IEE Proc.-Radar Sonar Navig., October 2004, Vol. 151, No. 5, pp. 249-260

2 WEIMING, Y.: 'Study on the design method of quasi-CW radar waveform', International Conference on Radar 2006, CIE '06, October 2006, Shanghai, China, pp. 1-4

3 PORTER, N.J., TOUGH, R.J.A., and WARD, K.D.: 'Properties and application of a randomly interrupted, random radar waveform', International Conference Radar 92, 12-13 October 1992, pp. 5-8

4 LEVANON, N., and MOZESON, E.: 'Radar signals' (Wiley-Interscience, 2004), pp. 210-212

5 LE CHEVALIER, F.: 'Principles of radar and sonar signal processing' (Artech House, 2002), pp. 31-33

6 PURSHOUSE, R.C., and FLEMING, P.J.: 'Conflict, harmony, and independence: relationships in evolutionary multi-criterion optimisation', Evolutionary Multi-Criterion Optimization Second International Conference, EMO 2003, Faro, Portugal, Springer, Lecture Notes in Computer Science, Volume 2632, April 2003, pp. 16-30

\section{Authors' affiliations:}

Rami Kassab and M. Lesturgie (SONDRA/ONERA, Palaiseau, France)

Jocelyn Fiorina (Telecommunication Department/ Supelec, Gif sur Yvette, France)

E-mail: rami.kassab@onera.fr 


\section{Figure captions:}

Fig. 1 Optimised signal's envelope

Fig. 2 Energy profile against distance bins

Fig. 3 Probabilities of detection against distance bins

$-P_{f a}$ of $10^{-2}$
$----P_{f a}$ of $10^{-5}$ 
Figure 1

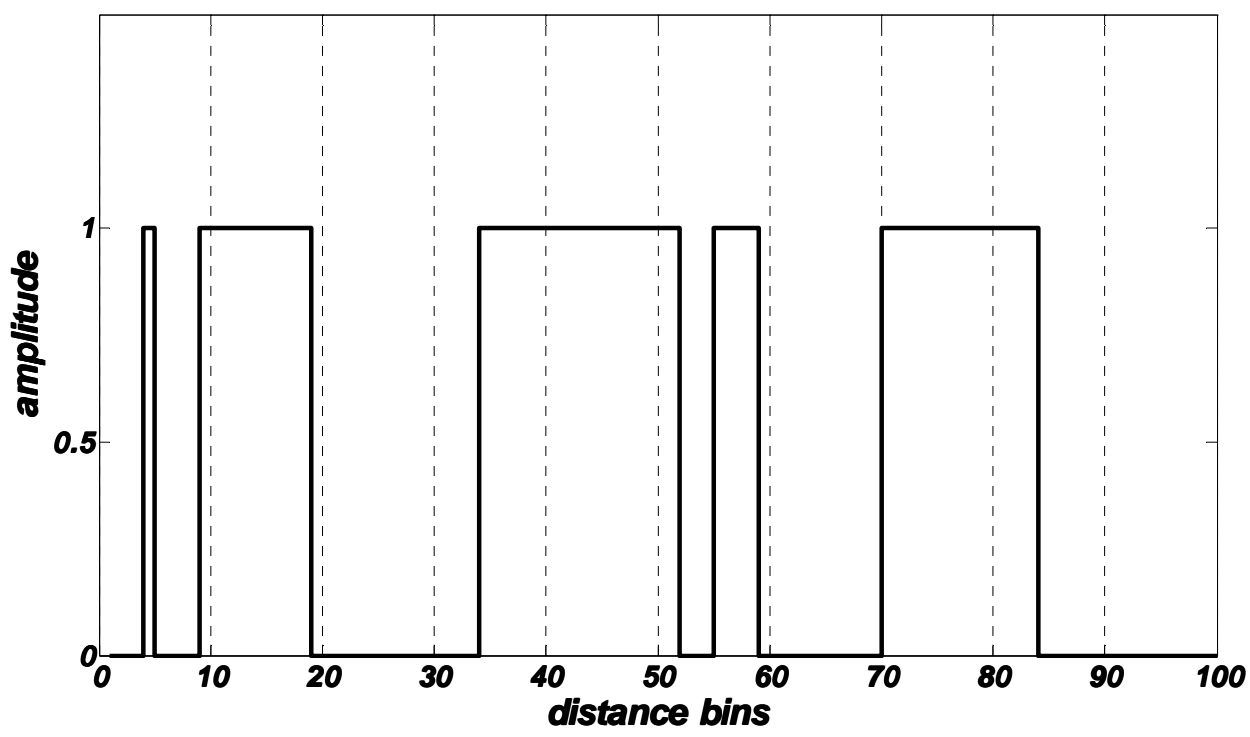


Figure 2

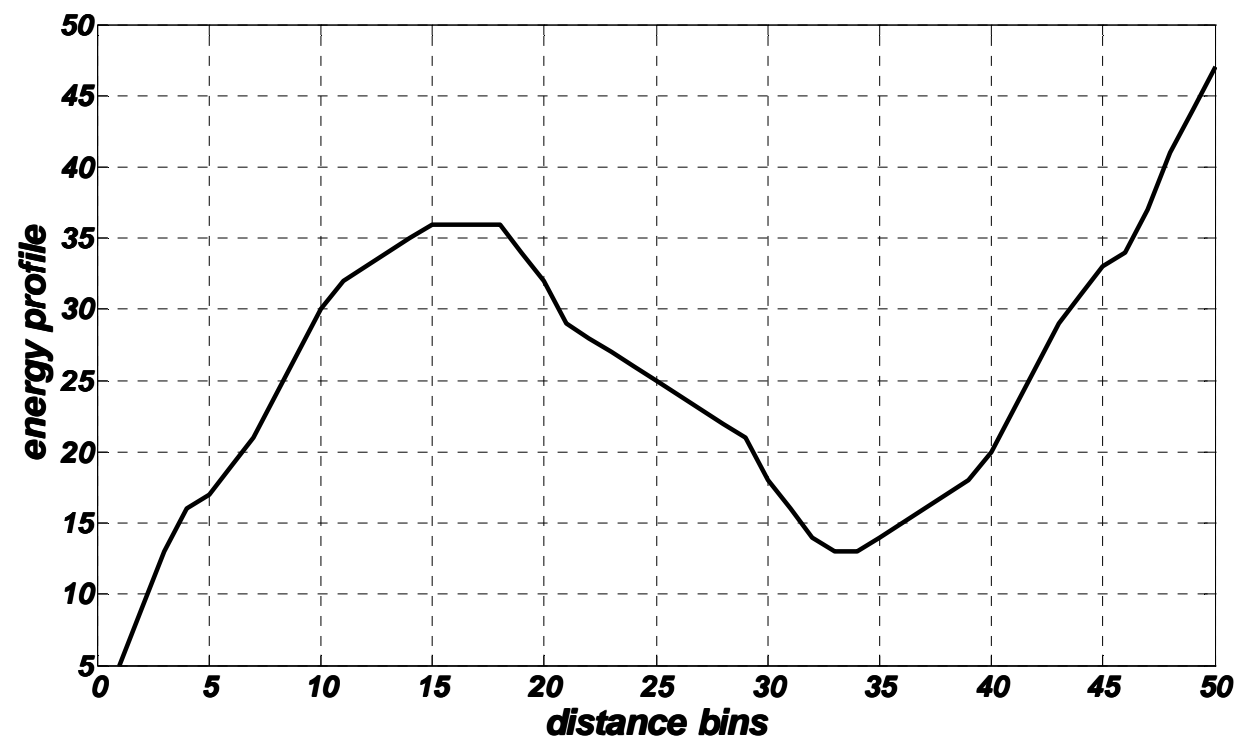


Figure 3

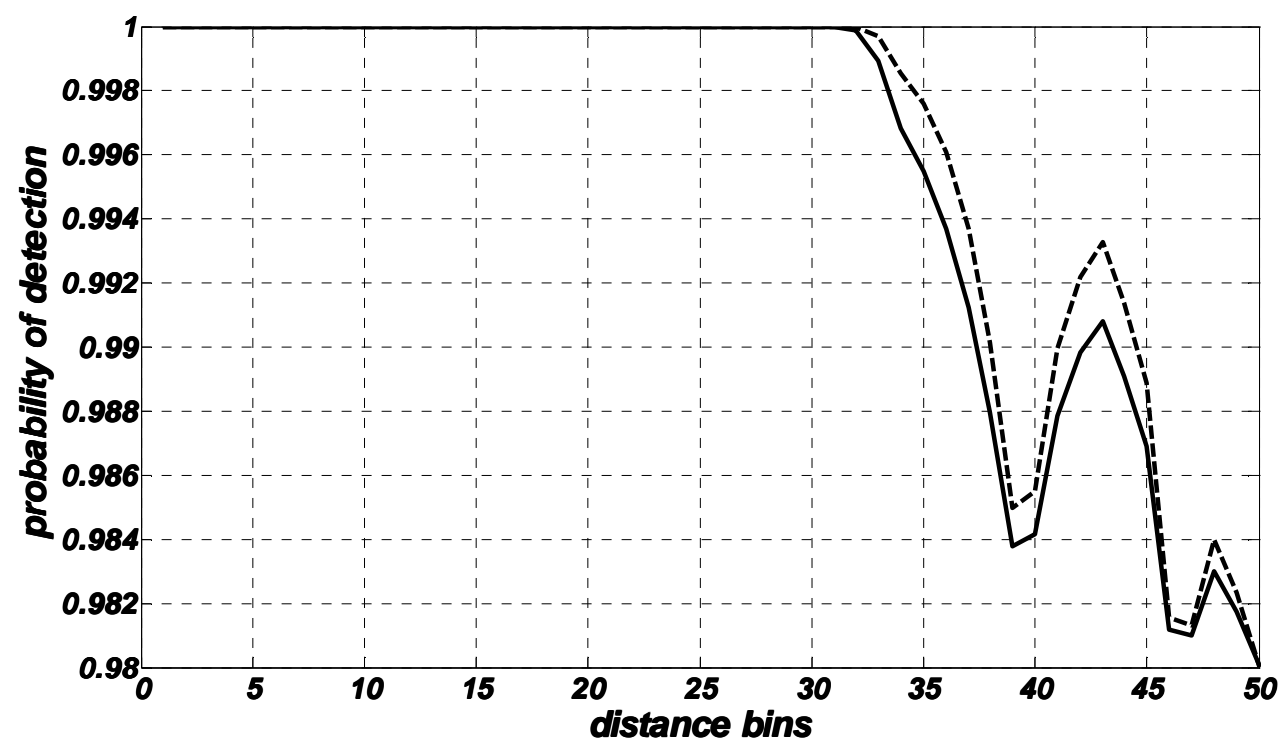

